\title{
EDITORIAL
}

\section{MATERNAL INVOLVEMENT IN GROWTH MONITORING}

As a result of problems identified in regard to the Road to Health Care by Nurse Researchers in the Child Health Research Programme at the Valley Trust, a letter was written to the Director of TALC on behalf of this programme by Dr. Georgina Lambert who is the Research Officer at the Valley Trust. The response from TALC was from the accepted world expert on growth monitoring, Professor David Morley. As his response to Dr Lambert's letter is of such relevance to Child Health Programmes and is of importance in current health care delivery in South Africa, this letter which follows is published below. Two references which pertain to this letter as well as TALC's address are incorporated at the end of this editorial.

The so-called 'Road to Health Charts' were home-based weight for age charts first developed by myself in West Africa in the late '50s. Since then, they have been widely adopted and became part of UNICEF's "G O B I" - Growth Monitoring, oral rehydration, breast-feeding and immunisation - programme.

However, right across the world it has become apparent that this growth monitoring is not well undertaken and does not fulfil its purpose of helping health workers to understand the growth of a child and to take the steps necessary to see that the child is growing properly.

It is only recently that the reason for this, I think, has been understood and this is that the concept of a line graph is one of the most difficult in all of education. There is no graph paper in most primary schools and 'meaning' of a line graph is not widely understood by most health workers and even a proportion of doctors.

Fortunately, a new method of weighing children has been recently developed which promises to overcome this. With this method, the mothers, themselves, plot the next dot on the child's growth curve and can compare it with the previous month's. This is described in the enclosed papers and I am very much hoping that with the use of this new type of weighing scale, which is now available from TALC, growth monitoring will take its proper place as the growth chart becomes central in the mother's whole involvement in primary health care. I hope other things such as Vit.A giving, and immunisation can also be recorded by the mother. She would pencil in the symbols shown by injections at the top of the chart".

Meegan M., Morley, D.C., \& Brown R. (1994). Child weighing by the unschooled: a report of a controlled study of growth monitoring over 12 months of Masaai children using direct recording scales. Transactions of the Royal Society of Tropical Medicine and Hygiene 88,1-2.

Morley D., (1994). Will growth monitoring continue to be part of primary health care? Supplement to $S A M J$ $84,(77), 15-16$.

Additional information can be obtained from: TALC, P. O. BO 49, ST. ALI LAX, England Tel: (0944) 727853869

Heidi Brookes Department of Nursing. University of Natal's participant on Valley Trust Child Healih Research Programme. 